\title{
On the split equality common fixed point problem for quasi-nonexpansive multi-valued mappings in Banach spaces
}

\author{
Xuejin Tian ${ }^{a}$, Lin Wang ${ }^{a, *}$, Zhaoli Ma ${ }^{b}$ \\ ${ }^{a}$ College of Statistics and Mathematics, Yunnan University of Finance and Economics, Kunming, Yunnan, 650221, P. R. China. \\ ${ }^{b}$ Department of General Education, The College of Arts and Sciences Yunnan Normal University, Kunming, Yunnan, 650222, P. R. \\ China.
}

Communicated by Y. J. Cho

\begin{abstract}
The purpose of this paper is to study the split equality common fixed point problems of quasi-nonexpansive multi-valued mappings in the setting of Banach spaces. For solving this kind of problems, some new iterative algorithms are proposed. Under suitable conditions, some weak and strong convergence theorems for the sequences generated by the proposed algorithm are proved. The results presented in this paper are new which also improve and extend some recent results announced by some authors. (c)2016 All rights reserved.
\end{abstract}

Keywords: Split equality problem, quasi-nonexpansive multi-valued mapping, weak convergence, strong convergence.

2010 MSC: 47J25, 47H09, 65K10.

\section{Introduction}

Let $C$ and $Q$ be two nonempty closed convex subsets of real Hilbert spaces $H_{1}$ and $H_{2}$, respectively. The split feasibility problem (SFP) can be formulated as

$$
\text { find } x \in C \text { such that } A x \in Q \text {, }
$$

\footnotetext{
* Corresponding author

Email addresses: 1099439905@qq.com (Xuejin Tian), WL64mail@aliyun.com (Lin Wang), kmszmzl@126.com (Zhaoli Ma)
} 
where $A: H_{1} \rightarrow H_{2}$ is a bounded linear operator. The split feasibility problem (SFP) in finitely dimensional spaces was firstly introduced by Censor and Elfving [4] for modeling inverse problems which arise from phase retrievals and in medical image reconstruction [2]. The SFP has attracted much attentions because of its applications in modeling inverse problems, radiation therapy treatment planning and signal processing [3] 6 . Some methods have been proposed to solve split feasibility problems in [13, 18, 19].

Assume that SFP 1.1) is consistent, it is not hard to see that the solution set of SFP (1.1) (i.e., $\{x \in C: A x \in Q\})$ is closed and convex. The SFP can be solved by the CQ algorithm, which was firstly proposed by Byrne [2]:

$$
x_{k+1}=P_{C}\left(I-\gamma A^{*}\left(I-P_{Q}\right) A\right) x_{k}, \quad k \geq 1,
$$

where $\gamma \in\left(0, \frac{2}{\|A\|^{2}}\right)$ with $\lambda$ being the spectral radius of the operator $A^{*} A, P_{C}$ and $P_{Q}$ are the metric projections from $H_{1}$ onto $C$ and from $H_{2}$ onto $Q$, respectively.

If $C$ and $Q$ are sets of fixed points of two nonlinear mappings, respectively, and $C$ and $Q$ are nonempty closed convex subsets, then $q$ is said to be a split common fixed point for the two nonlinear mappings. That is, the split common fixed point problem (SCFP) for mappings $S$ and $T$ is to find a point $q \in H_{1}$ with the property:

$$
q \in C:=F(S) \text { and } A q \in Q:=F(T),
$$

where $F(S)$ and $F(T)$ denote the sets of fixed points of $S$ and $T$, respectively.

Since each nonempty closed convex subset of a Hilbert space is the set of fixed points of its projection, so the split common fixed point problem can be considered as a generalization of the split feasibility problem and the convex feasibility problem. The split common fixed point problem was introduced by Moudafi [10] in 2010. In [10, Moudafi proposed an iteration scheme and obtained a weak convergence theorem of the split common fixed point problem for demicontractive mappings in the setting of two Hilbert spaces. Since then, the split common fixed point problems of other nonlinear mappings in the setting of two Hilbert spaces have been studied by some authors, see, for instance, [7, 8, 10, 11, 13, 14, 20.

Recently, Moudafi [12] proposed the split equality problem (SEP):

$$
\text { find } x \in C \text { and } y \in Q \text { such that } A x=B y \text {, }
$$

where $A: H_{1} \rightarrow H_{3}$ and $B: H_{2} \rightarrow H_{3}$ are two bounded linear operators, $C$ and $Q$ are two nonempty closed convex subsets of $H_{1}$ and $H_{2}$, respectively. We use $\Gamma$ to denote the set of solution of SEP (1.3), that is, $\Gamma=\{(p, q): p \in C, q \in Q, A p=B q\}$.

It is obvious that if $B=I$ and $H_{3}=H_{2}$, then SEP (1.3) can be reduced to SFP (1.1). The split equality problem (1.2) allows asymmetric and partial relations between the variables $x$ and $y$. The interest is to cover many situations such as decomposition methods for PDEs, applications in game theory, intensitymodulated radiation therapy. In decision sciences, this allows one to consider agents who interplay only via some components of their decision variables [1].

In order to solve SEP (1.3), Moudafi [12] proposed the following alternating CQ-algorithm (ACQA) and relaxed alternating CQ-algorithm (RACQA), i.e.,

$$
A C Q A:\left\{\begin{array}{l}
x_{k+1}=P_{C}\left(x_{k}-\gamma_{k} A^{*}\left(A x_{k}-B y_{k}\right)\right) \\
y_{k+1}=P_{Q}\left(y_{k}+\gamma_{k} B^{*}\left(A x_{k}-B y_{k}\right)\right)
\end{array}\right.
$$

and

$$
R A C Q A:\left\{\begin{array}{l}
x_{k+1}=P_{C_{k}}\left(x_{k}-\gamma A^{*}\left(A x_{k}-B y_{k}\right)\right), \\
y_{k+1}=P_{Q_{k}}\left(y_{k}+\beta B^{*}\left(A x_{k}-B y_{k}\right)\right),
\end{array}\right.
$$

under appropriate conditions, the author proved that the iterative schemes above converge weakly to a solution of the SEP (1.3).

Definition 1.1. Let $E$ be a real Banach space and $S: E \rightarrow C B(E)$ be a multi-valued mapping. $S$ is said to be

(1) nonexpansive, if $H(S x, S y) \leq\|x-y\|$, for all $x, y \in E$;

(2) quasi-nonexpansive, if $F(S) \neq \emptyset$ and $H(S x, S z) \leq\|x-z\|$, for all $x \in E$ and $z \in F(S)$, 
where $F(S)$ denotes the fixed points set of $S$, the Hausdorff metric on $C B(E)$ (which stands for the collection of all nonempty closed bounded subsets of $E$ ) is indicated by

$$
H(C, D)=\max \left\{\sup _{x \in C} d(x, D), \sup _{y \in D} d(y, C)\right\}, C, D \in C B(E),
$$

where $d(x, D)=\inf _{y \in D} d\|x-y\|$.

Recently, Wu et al. [16] proposed an iterative algorithm to study the convergence results of split equality common fixed point problem for quasi-nonexpansive multi-valued mappings in Hilbert spaces, and obtained the following result.

Theorem 1.2 (Theorem 2.3 of [16]). Let $H_{1}, H_{2}, H_{3}$ be Hilbert spaces, $A: H_{1} \rightarrow H_{3}, B: H_{2} \rightarrow H_{3}$ be two bounded linear operators, $R_{1}: H_{1} \rightarrow C B\left(H_{1}\right)$ and $R_{2}: H_{2} \rightarrow C B\left(H_{2}\right)$ be two quasi-nonexpansive multi-valued mappings, $C=F\left(R_{1}\right), Q=F\left(R_{2}\right)$. Suppose that $0<\liminf _{n \rightarrow \infty} \alpha_{n} \leq \lim _{\sup _{n \rightarrow \infty}} \alpha_{n}<1$ and $R_{1}, R_{2}$ are demi-closed at the origin, the sequence $\left\{w_{n}\right\}$ is generated by

$$
w_{n+1}=\alpha_{n}\left(I-\gamma G^{*} G\right) w_{n}+\left(1-\alpha_{n}\right) v_{n}, \quad v_{n} \in R\left(w_{n}-\gamma G^{*} G w_{n}\right),
$$

where $\left\{\alpha_{n}\right\} \subseteq(0,1)$ and $\gamma \in\left(0, \frac{2}{\rho\left(G^{*} G\right)}\right)$ with $\rho\left(G^{*} G\right)$ being the spectral radius of the self-adjoint operator $G^{*} G$ on $H$. Define $G: H \rightarrow H_{3}$ by $G=[A,-B], R: H_{1} \times H_{2} \rightarrow H_{1} \times H_{2}$ by

$$
\left(\begin{array}{cc}
R_{1} & 0 \\
0 & R_{2}
\end{array}\right)
$$

Then the sequence $\left\{w_{n}\right\}$ defined by (1.4) converges weakly to a solution of SEP (1.3). In addition, if $R_{1}, R_{2}$ are semi-compact, then the sequence $\left\{w_{n}\right\}$ converges strongly to a solution of SEP (1.3).

Very recently, in [15], Tang et al. proposed an iteration method to approximate a solution of the SCFP (1.2) for strict pseudocontractive mapping and asymptotically nonexpansive mappings in the setting of two Banach spaces, and obtained the strong and weak convergence theorems of iteration scheme proposed.

Naturally, the facts above remain us the following question:

Can the convergence theorems for a solution of the split equality common fixed point problem for quasinonexpansive multi-valued mapping be obtained in Banach spaces?

In this paper, we propose the following iterative algorithm to approximate a split equality common fixed point of quasi-nonexpansive multi-valued mappings in Banach spaces. For any $x_{0} \in E_{1}$ and $y_{0} \in E_{2}$, the sequence $\left\{\left(x_{n}, y_{n}\right)\right\}$ is generated by

$$
\left\{\begin{array}{l}
u_{n} \in S_{1}\left(x_{n}-\gamma J_{1}^{-1} A^{*} J_{3}\left(A x_{n}-B y_{n}\right)\right), \\
v_{n} \in S_{2}\left(y_{n}+\gamma J_{2}^{-1} B^{*} J_{3}\left(A x_{n}-B y_{n}\right)\right) \\
y_{n+1}=\left(1-\beta_{n}\right) v_{n}+\beta_{n}\left(x_{n}+\gamma J_{2}^{-1} B^{*} J_{3}\left(A x_{n}-B y_{n}\right)\right), \\
x_{n+1}=\left(1-\beta_{n}\right) u_{n}+\beta_{n}\left(x_{n}-\gamma J_{1}^{-1} A^{*} J_{3}\left(A x_{n}-B y_{n}\right)\right),
\end{array}\right.
$$

where $E_{1}, E_{2}, E_{3}$ are three Banach spaces, $A: E_{1} \rightarrow E_{3}, B: E_{2} \rightarrow E_{3}$ are two bounded linear operators, $S_{1}: E_{1} \rightarrow C B\left(E_{1}\right), S_{2}: E_{2} \rightarrow C B\left(E_{2}\right)$ are two quasi-nonexpansive multi-valued mappings and $C=F\left(S_{1}\right)$, $Q=F\left(S_{2}\right)$. In the rest of this paper, we still denote the set of solutions of SEP (1.3) by $\Gamma=\{(x, y) \in$ $\left.E_{1} \times E_{2}, A x=B y, x \in C, y \in D\right\}$. Under some mild conditions, we obtain the strong and weak convergence of the iterative scheme above in Banach spaces.

\section{Preliminaries}

Throughout this paper, the set of fixed points of $S$ is denoted by $F(S)$ and the strong convergence and weak convergence of a sequence $\left\{x_{n}\right\}$ to a point $x \in E$ is denoted by $x_{n} \rightarrow x$ and $x_{n} \rightarrow x$, respectively. Let $E$ be a real Banach space with the dual $E^{*}$. The normalized duality mapping $J: E \rightarrow 2^{E^{*}}$ is defined by

$$
J x=\left\{f \in E^{*}:\langle x, f\rangle=\|x\|^{2}=\|f\|^{2}\right\}, \quad x \in E,
$$


where $\langle\cdot, \cdot\rangle$ is the generalized duality pairing between $E$ and $E^{*}$.

A Banach space $E$ is said to be strictly convex, if $\frac{\|x+y\|}{2}<1$ for all $x, y \in U=\{z \in E:\|z\|=1\}$ with $x \neq y$.

A Banach space $E$ is said to be uniformly convex, if for each $\varepsilon \in(0,2]$, there exists $\delta>0$ such that $\frac{\|x+y\|}{2} \leq 1-\delta$ for all $x, y \in U$ with $\|x-y\|>\varepsilon$.

A Banach space $E$ is said to be smooth, if the $\operatorname{limit}_{\lim } \lim _{t \rightarrow 0} \frac{\|x+t y\|-\|x\|}{t}$ exists for all $x, y \in U$. A Banach space $E$ is said to be uniformly smooth, if $\frac{\rho_{E}(t)}{t} \rightarrow 0$ as $t \rightarrow 0$, where the modulus of smoothness $\rho_{E}:[0, \infty) \rightarrow[0, \infty)$ is defined by

$$
\rho_{E}(t)=\sup \left\{\frac{(\|x+y\|+\|x-y\|)}{2}-1: x \in U,\|y\| \leq t\right\} .
$$

A Banach space $E$ is said to be $p$-uniformly smooth (let $p>1$ be a fixed number), if there exists a constant $c>0$ such that $\rho_{E}(t) \leq c t^{p}$ for all $t>0$.

Remark 2.1 ([9]). The basic properties of Banach space $E$ are as follows:

(1) A uniformly convex Banach space is strictly convex and reflective.

(2) If $E$ is a smooth, reflexive and strictly convex Banach space, then the normalized duality mapping $J$ from $E$ to $2^{E^{*}}$ is single-valued, one-to-one, and surjective.

(3) If $E$ is an uniformly smooth Banach space, then the normalized duality mapping $J$ is uniformly continuous on every bounded subset of $E$.

(4) A Banach space $E$ is uniformly smooth, if and only if its dual $E^{*}$ is uniformly convex.

(5) Each uniformly convex Banach space $E$ has the Kadec-Klee property, i.e., $x_{n} \rightarrow u \in E$ and $\left\|x_{n}\right\| \rightarrow\|u\|$ imply $x_{n} \rightarrow u$.

(6) It is common knowledge that every $p$-uniformly smooth Banach space is uniformly smooth.

Lemma 2.2 ([17]). Let $E$ be a uniformly convex Banach space. For any given number $r>0$, there exists a continuous strictly increasing function $g:[0, \infty) \rightarrow[0, \infty), g(0)=0$ such that

$$
\|t x+(1-t) y\|^{2} \leq t\|x\|^{2}+(1-t)\|y\|^{2}-t(1-t) g(\|x-y\|)
$$

for all $x, y \in E$ with $\|x\| \leq r,\|y\| \leq r$ and $t \in[0,1]$.

Lemma 2.3 ([17]). Let $E$ be a 2-uniformly smooth Banach space with the best smoothness constant $k>0$. Then the following inequality holds:

$$
\|x+y\|^{2} \leq\|x\|^{2}+2\langle y, J x\rangle+2\|k y\|^{2}, \quad x, y \in E .
$$

Definition 2.4 ([16]). A multi-valued mapping $S: E \rightarrow C B(E)$ is said to be demi-closed at zero, if for any $\left\{x_{n}\right\} \subseteq E$ such that $x_{n} \rightarrow x$ and $d\left(x_{n}, S x_{n}\right) \rightarrow 0$, then $x \in S x$.

Definition 2.5 ([16]). Let $E$ be a Banach space. A multi-valued mapping $S: E \rightarrow C B(E)$ is said to be semi-compact, if for any bounded sequence $\left\{x_{n}\right\} \subseteq E$ such that $d\left(x_{n}, S x_{n}\right) \rightarrow 0$, there exists a subsequence $\left\{x_{n_{j}}\right\}$ of $\left\{x_{n}\right\}$ such that $x_{n_{j}} \rightarrow x \in E$.

\section{Main results}

Theorem 3.1. Let $E_{1}, E_{2}$ be real uniformly convex and 2-uniformly smooth Banach spaces with the best smoothness constant $k \in\left(0, \frac{1}{\sqrt{2}}\right), E_{3}$ be a real Banach space, $S_{1}: E_{1} \rightarrow C B\left(E_{1}\right)$ and $S_{2}: E_{2} \rightarrow C B\left(E_{2}\right)$ be two quasi-nonexpansive multi-valued mappings, respectively. Let $A: E_{1} \rightarrow E_{3}$ and $B: E_{2} \rightarrow E_{3}$ be two bounded linear operators. For any $\left(x_{0}, y_{0}\right) \in E_{1} \times E_{2}$, the sequence $\left\{\left(x_{n}, y_{n}\right)\right\}$ is generated by 


$$
\left\{\begin{array}{l}
u_{n} \in S_{1}\left(x_{n}-\gamma J_{1}^{-1} A^{*} J_{3}\left(A x_{n}-B y_{n}\right)\right), \\
v_{n} \in S_{2}\left(y_{n}+\gamma J_{2}^{-1} B^{*} J_{3}\left(A x_{n}-B y_{n}\right)\right), \\
y_{n+1}=\left(1-\beta_{n}\right) v_{n}+\beta_{n}\left(x_{n}+\gamma J_{2}^{-1} B^{*} J_{3}\left(A x_{n}-B y_{n}\right)\right), \\
x_{n+1}=\left(1-\beta_{n}\right) u_{n}+\beta_{n}\left(x_{n}-\gamma J_{1}^{-1} A^{*} J_{3}\left(A x_{n}-B y_{n}\right)\right),
\end{array}\right.
$$

where $S_{1}, S_{2}$ are demi-closed at zero, $\left\{\beta_{n}\right\} \subseteq(0,1)$ satisfying $\liminf _{n \rightarrow \infty} \beta_{n}\left(1-\beta_{n}\right)>0,0<\gamma<\frac{1}{\max \left\{\lambda_{A}, \lambda_{B}\right\}}$ and $\lambda_{A}, \lambda_{B}$ stand for the spectral radius of $A^{*} A$ and $B^{*} B$, respectively. If $\Gamma=\left\{\left(x^{*}, y^{*}\right) \in E_{1} \times E_{2}: A x^{*}=\right.$ $\left.B y^{*}, x^{*} \in C, y^{*} \in D\right\} \neq \emptyset$, where $C:=F i x\left(S_{1}\right)$ and $Q:=F i x\left(S_{2}\right)$, then

(I) the sequence $\left\{\left(x_{n}, y_{n}\right)\right\}$ converges weakly to a solution $\left(x^{*}, y^{*}\right) \in \Gamma$ of SEP (1.3);

(II) In addition, if $S_{1}, S_{2}$ are semi-compact, then the sequence $\left\{\left(x_{n}, y_{n}\right)\right\}$ converges strongly to a solution $\left(x^{*}, y^{*}\right) \in \Gamma$ of $S E P(1.3)$.

Proof. For the sake of convenience, set $t_{n}=x_{n}-\gamma J_{1}^{-1} A^{*} J_{3}\left(A x_{n}-B y_{n}\right), w_{n}=y_{n}+\gamma J_{2}^{-1} B^{*} J_{3}\left(A x_{n}-B y_{n}\right)$ and $L=\max \left\{\lambda_{A}, \lambda_{B}\right\}$. Let $(x, y) \in \Gamma$, it follows from Lemma 2.2 that

$$
\begin{aligned}
\left\|x_{n+1}-x\right\|^{2} & =\left\|\beta_{n} t_{n}+\left(1-\beta_{n}\right) u_{n}-z\right\|^{2} \\
& =\left\|\beta_{n}\left(t_{n}-x\right)+\left(1-\beta_{n}\right)\left(u_{n}-x\right)\right\|^{2} \\
& \leq \beta_{n}\left\|t_{n}-x\right\|^{2}+\left(1-\beta_{n}\right)\left\|u_{n}-x\right\|^{2}-\beta_{n}\left(1-\beta_{n}\right) g\left(\left\|t_{n}-u_{n}\right\|\right) \\
& \leq \beta_{n}\left\|t_{n}-x\right\|^{2}+\left(1-\beta_{n}\right) H\left(S_{1} t_{n}, S_{1} x\right)^{2}-\beta_{n}\left(1-\beta_{n}\right) g\left(\left\|t_{n}-u_{n}\right\|\right) \\
& \leq \beta_{n}\left\|t_{n}-x\right\|^{2}+\left(1-\beta_{n}\right)\left\|t_{n}-x\right\|^{2}-\beta_{n}\left(1-\beta_{n}\right) g\left(\left\|t_{n}-u_{n}\right\|\right) \\
& =\left\|t_{n}-x\right\|^{2}-\beta_{n}\left(1-\beta_{n}\right) g\left(\left\|t_{n}-u_{n}\right\|\right) .
\end{aligned}
$$

Further, from Lemma 2.3 , we have

$$
\begin{aligned}
\left\|t_{n}-x\right\|^{2} & =\left\|x_{n}-\gamma J_{1}^{-1} A^{*} J_{3}\left(A x_{n}-B y_{n}\right)-x\right\|^{2} \\
& =\left\|\gamma J_{1}^{-1} A^{*} J_{3}\left(A x_{n}-B y_{n}\right)+\left(x-x_{n}\right)\right\|^{2} \\
& \leq\left\|\gamma J_{1}^{-1} A^{*} J_{3}\left(A x_{n}-B y_{n}\right)\right\|^{2}+2 \gamma\left\langle x-x_{n}, J_{1} J_{1}^{-1} A^{*} J_{3}\left(A x_{n}-B y_{n}\right)\right\rangle+2 k^{2}\left\|x-x_{n}\right\|^{2} \\
& \leq \gamma^{2} L\left\|A x_{n}-B y_{n}\right\|^{2}+2 \gamma\left\langle A x-A x_{n}, J_{3}\left(A x_{n}-B y_{n}\right)\right\rangle+2 k^{2}\left\|x-x_{n}\right\|^{2} .
\end{aligned}
$$

So, it follows from 3.1 and 3.2 that

$$
\begin{aligned}
\left\|x_{n+1}-x\right\|^{2} \leq & \gamma^{2} L\left\|A x_{n}-B y_{n}\right\|^{2}+2 \gamma\left\langle A x-A x_{n}, J_{3}\left(A x_{n}-B y_{n}\right)\right\rangle \\
& +2 k^{2}\left\|x-x_{n}\right\|^{2}-\beta_{n}\left(1-\beta_{n}\right) g\left(\left\|t_{n}-u_{n}\right\|\right) .
\end{aligned}
$$

Similarly, we can get

$$
\begin{aligned}
\left\|y_{n+1}-y\right\|^{2} \leq & \gamma^{2} L\left\|A x_{n}-B y_{n}\right\|^{2}+2 \gamma\left\langle B y_{n}-B y, J_{3}\left(A x_{n}-B y_{n}\right)\right\rangle \\
& +2 k^{2}\left\|y-y_{n}\right\|^{2}-\beta_{n}\left(1-\beta_{n}\right) g\left(\left\|w_{n}-v_{n}\right\|\right) .
\end{aligned}
$$

By adding (3.3) and (3.4), since $A x=B y$, we have

$$
\begin{aligned}
\| x_{n+1}- & x\left\|^{2}+\right\| y_{n+1}-y \|^{2} \\
\leq & 2 \gamma^{2} L\left\|A x_{n}-B y_{n}\right\|^{2}+2 \gamma\left\langle-\left(A x_{n}-B y_{n}\right), J_{3}\left(A x_{n}-B y_{n}\right)\right\rangle \\
& +2 k^{2}\left(\left\|x-x_{n}\right\|^{2}+\left\|y-y_{n}\right\|^{2}\right)-\beta_{n}\left(1-\beta_{n}\right)\left[g\left(\left\|t_{n}-u_{n}\right\|\right)+g\left(\left\|w_{n}-v_{n}\right\|\right)\right] .
\end{aligned}
$$

Now, set $W_{n}(x, y)=\left\|x_{n}-x\right\|^{2}+\left\|y_{n}-y\right\|^{2}$, it follows (3.5) that

$$
\begin{aligned}
W_{n+1}(x, y) \leq & 2 k^{2} W_{n}(x, y)-2 \gamma(1-\gamma L)\left\|A x_{n}-B y_{n}\right\|^{2} \\
& -\beta_{n}\left(1-\beta_{n}\right)\left[g\left(\left\|t_{n}-u_{n}\right\|\right)+g\left(\left\|w_{n}-v_{n}\right\|\right)\right] .
\end{aligned}
$$


Since $0<\gamma<\frac{1}{\max \left\{\lambda_{A}, \lambda_{B}\right\}}, L=\max \left\{\lambda_{A}, \lambda_{B}\right\}$ and $k \in\left(0, \frac{1}{\sqrt{2}}\right)$, we can obtain

$$
W_{n+1}(x, y) \leq 2 k^{2} W_{n}(x, y) \leq W_{n}(x, y) .
$$

This implies that $\left\{W_{n}(x, y)\right\}$ is a non-increasing sequence, hence $\lim _{n \rightarrow \infty} W_{n}$ exists. From (3.6), we have

$$
\begin{aligned}
2 \gamma(1-\gamma L)\left\|A x_{n}-B y_{n}\right\|^{2} & +\beta_{n}\left(1-\beta_{n}\right)\left[g\left(\left\|t_{n}-u_{n}\right\|\right)+g\left(\left\|w_{n}-v_{n}\right\|\right)\right] \\
& \leq 2 k^{2} W_{n}(x, y)-W_{n+1}(x, y) \\
& \leq W_{n}(x, y)-W_{n+1}(x, y) .
\end{aligned}
$$

Therefore, we can obtain

$$
\lim _{n \rightarrow \infty} g\left(\left\|t_{n}-u_{n}\right\|\right)=0, \quad \lim _{n \rightarrow \infty} g\left(\left\|w_{n}-v_{n}\right\|\right)=0
$$

and

$$
\lim _{n \rightarrow \infty}\left\|A x_{n}-B y_{n}\right\|=0
$$

By Lemma 2.2, we have

$$
\lim _{n \rightarrow \infty}\left\|t_{n}-u_{n}\right\|=0 \quad \text { and } \quad \lim _{n \rightarrow \infty}\left\|w_{n}-v_{n}\right\|=0
$$

Since

$$
\left\|x_{n}-t_{n}\right\|=\left\|J_{1}\left(x_{n}-t_{n}\right)\right\|=\left\|\gamma A^{*} J_{3}\left(A x_{n}-B y_{n}\right)\right\| \leq \gamma\|A\|\left\|A x_{n}-B y_{n}\right\|,
$$

and

$$
\left\|y_{n}-w_{n}\right\|=\left\|J_{2}\left(y_{n}-w_{n}\right)\right\|=\left\|\gamma B^{*} J_{3}\left(A x_{n}-B y_{n}\right)\right\| \leq \gamma\|B\|\left\|A x_{n}-B y_{n}\right\|,
$$

from (3.7), we may get

$$
\lim _{n \rightarrow \infty}\left\|x_{n}-t_{n}\right\|=0 \quad \text { and } \quad \lim _{n \rightarrow \infty}\left\|y_{n}-w_{n}\right\|=0 .
$$

Now, we prove the conclusion (I).

Since $E_{1}$ and $E_{2}$ are uniformly convex, they are reflexive. On the other hand, since $\left\|x_{n}-x\right\|^{2} \leq W_{n}(x, y)$, $\left\|y_{n}-y\right\|^{2} \leq W_{n}(x, y)$ and $\lim _{n \rightarrow \infty} W_{n}$ exists, we know that $\left\{\left(x_{n}, y_{n}\right)\right\}$ is bounded. So we may assume that $\left(x^{*}, y^{*}\right)$ is weak cluster points of $\left\{\left(x_{n}, y_{n}\right)\right\}$. By (3.9), we know that $\left(x^{*}, y^{*}\right)$ also is weak cluster points of $\left\{\left(t_{n}, w_{n}\right)\right\}$. In addition, since $u_{n} \in S_{1} t_{n}$ and $v_{n} \in S_{2} w_{n}$, we have $d\left(t_{n}, S_{1} t_{n}\right) \leq\left\|t_{n}-u_{n}\right\|$ and $d\left(w_{n}, S_{2} w_{n}\right) \leq\left\|v_{n}-w_{n}\right\|$. So it follows from (3.8) that $\lim _{n \rightarrow \infty} d\left(t_{n}, S_{1} t_{n}\right)=0$ and $\lim _{n \rightarrow \infty} d\left(w_{n}, S_{2} w_{n}\right)=0$. Due to the demi-closed property of $S_{1}$ and $S_{2}$, we have $\left(x^{*}, y^{*}\right) \in C \times Q$, where $C:=\operatorname{Fix}\left(S_{1}\right), Q:=\operatorname{Fix}\left(S_{2}\right)$.

Since $A$ and $B$ are bounded linear operators, we know that $A x^{*}-B y^{*}$ is a weak cluster point of $\left\{A x_{n}-B y_{n}\right\}$. From the weakly lower semi-continuous property of the norm and (3.7), we get

$$
\left\|A x^{*}-B y^{*}\right\| \leq \liminf _{n \rightarrow \infty}\left\|A x_{n}-B y_{n}\right\|=0 .
$$

So, $A x^{*}=B y^{*}$. This implies $\left(x^{*}, y^{*}\right) \in\left\{(x, y) \in E_{1} \times E_{2}, A x=B y\right\}$. Hence

$$
\left(x^{*}, y^{*}\right) \in\left\{(x, y) \in E_{1} \times E_{2}: A x=B y, x \in C, y \in Q\right\} .
$$

We now prove that $\left(x^{*}, y^{*}\right)$ is the unique weak cluster point of $\left\{\left(x_{n}, y_{n}\right)\right\}$.

Let $(p, q)$ be another weak cluster point of $\left\{\left(x_{n}, y_{n}\right)\right\}$. Similarly, by the arguments above, we have $(p, q) \in \Gamma$, too. Notice that

$$
\begin{aligned}
W_{n}\left(x^{*}, y^{*}\right)= & \left\|x_{n}-x^{*}\right\|^{2}+\left\|y_{n}-y^{*}\right\|^{2} \\
= & \left\|x_{n}-p\right\|^{2}+2\left\langle x_{n}-p, J_{1}\left(p-x^{*}\right)\right\rangle+\left\|p-x^{*}\right\|^{2} \\
& +\left\|y_{n}-q\right\|^{2}+2\left\langle y_{n}-q, J_{2}\left(q-x^{*}\right)\right\rangle+\left\|q-y^{*}\right\|^{2}
\end{aligned}
$$




$$
=W_{n}(p, q)+2\left\langle x_{n}-p, J_{1}\left(p-x^{*}\right)\right\rangle+\left\|p-x^{*}\right\|^{2}+2\left\langle y_{n}-q, J_{2}\left(q-x^{*}\right)\right\rangle+\left\|q-y^{*}\right\|^{2} .
$$

Without loss of generality, we may assume that $\left\{\left(x_{n}, y_{n}\right)\right\}$ converges weakly to $(p, q)$. In addition, we also assume that $\lim _{n \rightarrow \infty} W_{n}\left(x^{*}, y^{*}\right)=W\left(x^{*}, y^{*}\right)$ and $\lim _{n \rightarrow \infty} W_{n}(p, q)=W(p, q)$. Thus, from the equality above, we have

$$
W\left(x^{*}, y^{*}\right)=W(p, q)+\left\|p-x^{*}\right\|^{2}+\left\|q-y^{*}\right\|^{2} .
$$

Similarly, we have

$$
W(p, q)=W\left(x^{*}, y^{*}\right)+\left\|p-x^{*}\right\|^{2}+\left\|q-y^{*}\right\|^{2} .
$$

It follows from 3.10 and 3.11 that

$$
\left\|p-x^{*}\right\|^{2}+\left\|q-y^{*}\right\|^{2}=0
$$

which means that $(p, q)=\left(x^{*}, y^{*}\right)$. The proof of conclusion (I) is completed.

Next, we prove (II). Due to $S_{1}, S_{2}$ are semi-compact, $\left\{\left(x_{n}, y_{n}\right)\right\}$ is bounded and $\lim _{n \rightarrow \infty} d\left(t_{n}, S_{1} t_{n}\right)=0$ and $\lim _{n \rightarrow \infty} d\left(w_{n}, S_{2} w_{n}\right)=0$, there exists subsequence $\left\{\left(t_{n_{j}}, w_{n_{j}}\right)\right\}$ of $\left\{\left(t_{n}, w_{n}\right)\right\}$ such that $\left\{\left(t_{n_{j}}, w_{n_{j}}\right)\right\}$ converges strongly to $\left(u^{*}, v^{*}\right)$. So, from the facts that $\lim _{n \rightarrow \infty}\left\|x_{n}-t_{n}\right\|=0$ and $\lim _{n \rightarrow \infty}\left\|y_{n}-w_{n}\right\|=0$, and $\left\{\left(x_{n}, y_{n}\right)\right\}$ converges weakly to $\left(x^{*}, y^{*}\right)$, we know that $\left(u^{*}, v^{*}\right)=\left(x^{*}, y^{*}\right)$. In addition, due to the definition of $\left\{\left(t_{n}, w_{n}\right)\right\}$ and

$$
\begin{aligned}
\left\|x_{n_{j}}-x^{*}\right\| & =\left\|x_{n_{j}}-t_{n_{j}}+t_{n_{j}}-x^{*}\right\| \\
& \leq\left\|\gamma J_{1}^{-1} A^{*} J_{3}\left(A x_{n_{j}}-B y_{n_{j}}\right)\right\|+\left\|t_{n_{j}}-x^{*}\right\| \\
& \leq \gamma\|A\|\left\|A x_{n_{j}}-B y_{n_{j}}\right\|+\left\|t_{n_{j}}-x^{*}\right\|,
\end{aligned}
$$

and

$$
\begin{aligned}
\left\|y_{n_{j}}-y^{*}\right\| & =\left\|y_{n_{j}}-w_{n_{j}}+w_{n_{j}}-y^{*}\right\| \\
& \leq\|\| \gamma J_{2}^{-1} B^{*} J_{3}\left(A x_{n_{j}}-B y_{n_{j}}\right)\|+\| w_{n_{j}}-x^{*} \| \\
& \leq \gamma\|B\|\left\|A x_{n_{j}}-B y_{n_{j}}\right\|+\left\|w_{n_{j}}-x^{*}\right\|,
\end{aligned}
$$

we obtain that $\lim _{n \rightarrow \infty}\left\|x_{n_{j}}-x^{*}\right\|=0$ and $\lim _{n \rightarrow \infty}\left\|y_{n_{j}}-y^{*}\right\|=0$.

On the other hand, since $W_{n}(x, y)=\left\|x_{n}-x\right\|^{2}+\left\|y_{n}-y\right\|^{2}$ for any $(x, y) \in \Omega$, we know that $\lim _{j \rightarrow \infty} W_{n_{j}}\left(x^{*}, y^{*}\right)=0$. From Conclusion (I), we know that $\lim _{n \rightarrow \infty} W_{n}\left(x^{*}, y^{*}\right)$ exists, therefore $\lim _{n \rightarrow \infty}$ $W_{n}\left(x^{*}, y^{*}\right)=0$. From the facts that $0 \leq\left\|x_{n}-x^{*}\right\| \leq W_{n}$ and $0 \leq\left\|y_{n}-y^{*}\right\| \leq W_{n}$, we can obtain that $\lim _{n \rightarrow \infty}\left\|x_{n}-x^{*}\right\|=0$ and $\lim _{n \rightarrow \infty}\left\|y_{n}-y^{*}\right\|=0$. This completes the proof of the conclusion (II).

For quasi-nonexpansive single-valued mappings, similar to the proofs in Theorem 3.1 , we can obtain the following result.

Theorem 3.2. Let $E_{1}, E_{2}$ be real uniformly convex and 2-uniformly smooth Banach spaces with the best smoothness constant $k \in\left(0, \frac{1}{\sqrt{2}}\right), E_{3}$ be a real Banach space, and $S_{1}: E_{1} \rightarrow E_{1}$ and $S_{2}: E_{2} \rightarrow E_{2}$ be two quasi-nonexpansive single-valued mappings, respectively. Let $A: E_{1} \rightarrow E_{3}$ and $B: E_{2} \rightarrow E_{3}$ be two bounded linear operators. For any $x_{0} \in E_{1}$ and $y_{0} \in E_{2}$, the sequence $\left\{\left(x_{n}, y_{n}\right)\right\}$ is generated by

$$
\left\{\begin{array}{l}
u_{n}=S_{1}\left(x_{n}-\gamma J_{1}^{-1} A^{*} J_{3}\left(A x_{n}-B y_{n}\right)\right), \\
v_{n}=S_{2}\left(y_{n}+\gamma J_{2}^{-1} B^{*} J_{3}\left(A x_{n}-B y_{n}\right)\right), \\
y_{n+1}=\left(1-\beta_{n}\right) v_{n}+\beta_{n}\left(x_{n}+\gamma J_{2}^{-1} B^{*} J_{3}\left(A x_{n}-B y_{n}\right)\right), \\
x_{n+1}=\left(1-\beta_{n}\right) u_{n}+\beta_{n}\left(x_{n}-\gamma J_{1}^{-1} A^{*} J_{3}\left(A x_{n}-B y_{n}\right)\right),
\end{array}\right.
$$

where $S_{1}, S_{2}$ are demi-closed at zero, $\left\{\beta_{n}\right\} \subseteq(0,1)$ satisfying $\liminf _{n \rightarrow \infty} \beta_{n}\left(1-\beta_{n}\right)>0,0<\gamma<\frac{1}{\max \left\{\lambda_{A}, \lambda_{B}\right\}}$ and $\lambda_{A}, \lambda_{B}$ stand for the spectral radius of $A^{*} A$ and $B^{*} B$, respectively. If $\Gamma=\left\{\left(x^{*}, y^{*}\right) \in E_{1} \times E_{2}: A x^{*}=\right.$ $\left.B y^{*}, x^{*} \in C, y^{*} \in D\right\} \neq \emptyset$, where $C:=\operatorname{Fix}\left(S_{1}\right), Q:=\operatorname{Fix}\left(S_{2}\right)$, then 
(I) the sequence $\left\{\left(x_{n}, y_{n}\right)\right\}$ converges weakly to a solution $\left(x^{*}, y^{*}\right) \in \Gamma$ of SEP (1.3);

(II) In addition, if $S_{1}, S_{2}$ are semi-compact, then the sequence $\left\{\left(x_{n}, y_{n}\right)\right\}$ converges strongly to a solution $\left(x^{*}, y^{*}\right) \in \Gamma$ of $S E P(1.3)$.

\section{Acknowledgment}

The authors wish to thank the editor and the referees for valuable suggestions. This work was supported by the National Natural Science Foundation of China (Grant No. 11361070).

\section{References}

[1] H. Attouch, J. Bolte, P. Redont, A. Soubeyran, Alternating proximal algorithms for weakly coupled convex minimization problems, Applications to dynamical games and PDE's, J. Convex Anal., 15 (2008), 485-506. 1

[2] C. Byrne, Iterative oblique projection onto convex sets and the split feasibility problem, Inverse Problems, 18 (2002), 441-453. 1

[3] Y. Censor, T. Bortfeld, B. Martin, A. Trofimov, A unified approach for inversion problems in intensity-modulated radiation therapy, Phys. Med. Biol., 51 (2006), 2353-2365. 1

[4] Y. Censor, T. Elfving, A multiprojection algorithm using Bregman projections in a product space, Numer. Algorithms, 8 (1994), 221-239. 1

[5] Y. Censor, T. Elfving, N. Kopf, T. Bortfeld, The multiple-sets split feasibility problem and its applications for inverse problems, Inverse Problems, 21 (2005), 2071-2084.

[6] Y. Censor, A. Motova, A. Segal, Perturbed projections and subgradient projections for the multiple-sets split feasibility problem, J. Math. Anal. Appl., 327 (2007), 1244-1256. 1

[7] S.-S. Chang, J. K. Kim, Y. J. Cho, J. Y. Sim, Weak- and strong-convergence theorems of solutions to split feasibility problem for nonspreading type mapping in Hilbert spaces, Fixed Point Theory Appl., 2014 (2014), 12 pages. 1

[8] S.-S. Chang, L. Wang, Y. K. Tang, L. Yang, The split common fixed point problem for total asymptotically strictly pseudocontractive mappings, J. Appl. Math., 2012 (2012), 13 pages. 1

[9] I. Cioranescu, Geometry of Banach spaces, duality mappings and nonlinear problems, Mathematics and its Applications, Kluwer Academic Publishers Group, Dordrecht, (1990) 2.1

[10] A. Moudafi, The split common fixed-point problem for demicontractive mappings, Inverse Problems, 26 (2010), 6 pages. 1

[11] A. Moudafi, A note on the split common fixed-point problem for quasi-nonexpansive operators, Nonlinear Anal., 74 (2011), 4083-4087. 1

[12] A. Moudafi, A relaxed alternating CQ-algorithm for convex feasibility problems, Nonlinear Anal., 79 (2013), 117-121. 1, 1

[13] B. Qu, N. H. Xiu, A note on the CQ algorithm for the split feasibility problem, Inverse Problems, 21 (2005), 1655-1665. 1, 1 ,

[14] J. Quan, S.-S. Chang, X. Zhang, Multiple-set split feasibility problems for $\kappa$-strictly pseudononspreading mapping in Hilbert spaces, Abstr. Appl. Anal., 2013 (2013), 5 pages. 1

[15] J. F. Tang, S.-S. Chang, L. Wang, X. R. Wang, On the split common fixed point problem for strict pseudocontractive and asymptotically nonexpansive mappings in Banach spaces, J. Inequal. Appl., 2015 (2015), 11 pages. 1

[16] Y. J. Wu, R. D. Chen, L. Y. Shi, Split equality problem and multiple-sets split equality problem for quasinonexpansive multi-valued mappings, J. Inequal. Appl., 2014 (2014), 8 pages. 1, 1.2, $2.4,2.5$

[17] H.-K. Xu, Inequalities in Banach spaces with applications, Nonlinear Anal., 16 (1991), 1127-1138. 2.2. 2.3

[18] H.-K. Xu, A variable Krasnoselskiu-Mann algorithm and the multiple-set split feasibility problem, Inverse Problems, 22 (2006), 2021-2034. 1

[19] Q. Z. Yang, The relaxed CQ algorithm solving the split feasibility problem, Inverse Problems, 20 (2004), 1261-1266. 1

[20] X.-F. Zhang, L. Wang, Z. L. Ma, L. J. Qin, The strong convergence theorems for split common fixed point problem of asymptotically nonexpansive mappings in Hilbert spaces, J. Inequal. Appl., 2015 (2015), 11 pages. 1 